\title{
UM ESTUDO DA UTILIZAÇÃO DA CONTROLADORIA NA GESTÃO HOSPITALAR
}

Vitor Hugo Bernardes Maino, Emerson Souza Neves, Sonia Sanae Sato

Universidade do Oeste Paulista - Unoeste, Curso de Administração, Presidente Prudente/SP. E-mail: vitormaino10@gmail.com,

\section{RESUMO}

A Controladoria pode embasar os gestores em suas tomadas de decisões, buscando a melhoria futura das organizações. Partindo desta explanação, foi realizada uma pesquisa com o objetivo de verificar se a Controladoria tem sido utilizada como ferramenta de tomada de decisão na gestão dos hospitais brasileiros e quais os benefícios advindos de sua utilização para essas organizações. Para o estudo foi efetuada uma pesquisa dos tipos qualitativa, exploratório-descritiva e bibliográfica. A pesquisa bibliográfica foi realizada por meio do levantamento dos artigos publicados em português na base de dados Google Acadêmico no período de 2012 a 2018. Os resultados encontrados demonstraram que de maneira geral, os hospitais fazem pouco uso dos instrumentos disponibilizados pela Controladoria. Assim, foi possível confirmar a hipótese do trabalho de que gestão dos hospitais faz uso da Controladoria em suas atividades de controle, porém não a utilizam em suas tomadas de decisões.

Palavras-chave: Contabilidade. Controladoria. Hospital. Instituições Hospitalares. Controladoria Hospitalar.

\section{A STUDY OF THE USE OF CONTROLLING IN HOSPITAL MANAGEMENT}

\section{ABSTRACT}

The Controllership can support managers in their decision-making, seeking the future improvement of organizations. Based on this explanation, a research was carried out with the objective of verifying that the Controllership has been used as a decision-making tool in the management of Brazilian hospitals and the benefits derived from its use for these organizations. For the study, a qualitative, exploratory-descriptive and bibliographic research was carried out. The bibliographic research was carried out by means of the survey of the articles published in Portuguese in the Scholar Google database from 2012 to 2018. The results found have shown that, in general, hospitals make little use of the instruments provided by the Controllership. Thus, it was possible to confirm the hypothesis of the work of which hospital management makes use of the Controllership in its control activities, but does not use it in its decision making.

Keywords: Accounting. Controllership. Hospital. Hospital Institution. Hospital Controllership.

\section{INTRODUÇÃO}

Assim como uma máquina que depende de diversas engrenagens para funcionar, o Estado Brasileiro considerado como a maior organização do Brasil, também depende de seus três poderes e de inúmeros órgãos públicos para seu perfeito funcionamento. Em linhas gerais, os órgãos públicos existem para cuidarem dos cidadãos brasileiros, portanto, eles são extremamente importantes para viabilizar a vida em sociedade, sobretudo, os hospitais que são organizações responsáveis pela assistência à saúde da população.
E para que os hospitais possam cumprir com a missão de garantir assistência médica aos cidadãos brasileiros, eles necessitam tomar diversas decisões rotineiramente, tais como, adquirir equipamentos de altos valores, manter elevados estoques de medicamentos, contratar e/ou demitir funcionários, entre outras.

Nesse contexto, destaca-se a Controladoria como uma importante ferramenta de gestão empresarial, que de acordo com Britto e Batista $(2008$, p. 14) "A Controladoria passa a ter um papel importante dentro de uma empresa direcionando e contribuindo, através de relatórios, os gestores para que alcancem 
otimização no resultado da organização". Assim, com base no exposto pelos autores, é possível aferir que a Controladoria visa a melhoria futura das organizações, por meio do suporte que oferece aos gestores em suas tomadas de decisões.

Partindo desta explanação, este trabalho levantou os seguintes problemas: A Controladoria tem sido utilizada pelos hospitais em suas tomadas de decisões? Quais as contribuições que os hospitais tem obtido com o uso da Controladoria?

Para responder a esses questionamentos, foi levantada a seguinte hipótese: A Controladoria tem sido utilizada pelos hospitais de maneira restrita, ou seja, apenas como um instrumento de controle e não de tomada de decisão. Deste modo, acredita-se que as contribuições advindas do uso da Controladoria nos hospitais não são significativas.

Como objetivo geral, o presente trabalho visa verificar se a Controladoria tem sido utilizada como ferramenta de tomada de decisão na gestão dos hospitais brasileiros e quais os benefícios advindos de sua utilização para estas organizações. Decorrente do objetivo geral, buscou-se atingir os seguintes objetivos específicos: apresentar a Controladoria dentro do contexto da Contabilidade; descrever o conceito, a importância e a função da Controladoria; identificar os instrumentos da Controladoria utilizados pela administração dos hospitais brasileiros; e discorrer sobre as contribuições da Controladoria.

\section{METODOLOGIA}

Essa pesquisa classifica-se como qualitativa, exploratório-descritiva e bibliográfica. Para Fachin (2006, p. 81) "a pesquisa qualitativa é identificada pelos seus atributos e não somente por aspectos mensuráveis [...]". Já a principal finalidade da pesquisa exploratório-descritiva segundo Marconi e Lakatos (2003, p. 107) “é a de observar os fatos, registrá-los, analisá-los, classificá-los e interpretá-los, sem a interferência do pesquisador". Quanto a pesquisa bibliográfica, de acordo com Vergara (1990, p. 12) esta referese a um "Estudo sistematizado desenvolvido a partir do material publicado em livros, revistas, jornais, isto é, material acessível ao público em geral".

Para a coleta de dados, incialmente foi realizada uma revisão bibliográfica preliminar sobre os assuntos Contabilidade e Controladoria, com o intuito dos pesquisadores obterem embasamento teórico sobre $\mathrm{o}$ assunto. Posteriormente foi realizada uma revisão bibliográfica aprofundada dos artigos publicados na base de dados Google Acadêmico no período de 2012 a 2018 visando a identificação e análise do que foi produzido pela comunidade acadêmica sobre a utilização da Controladoria pelos hospitais.

\section{RESULTADOS}

Os estudos sobre as civilizações antigas mostram que o homem primitivo já cuidava de sua riqueza por meio da contagem e do controle do seu rebanho. Embora tenha a sua origem perdida em tempos remotos, a Contabilidade começou a tomar corpo no Século XIII na Itália, e teve a sua primeira exposição na metade do Século XV quando da divulgação da obra do Frei Luca Pacioli, intitulada Tractatus de Computis et Scripturis (SILVA; SILVA NETO; CERQUEIRA, 2015).

Segundo Muller (2010, p. 1), "A contabilidade é, por definição, a ciência que estuda o desenvolvimento do patrimônio de uma pessoa, seus resultados e reflexos, sua evolução, sua gerência e seu futuro, conceito que deve ser entendido amplamente, e não de modo restrito".

Santos et. al. (2014, p. 5) comenta que "a contabilidade recebe e processa os dados da empresa. Após fazer isso, ela elabora as demonstrações financeiras, também conhecidas como relatórios". Nesse contexto, as principais funções da Contabilidade são registrar, organizar, demonstrar, analisar e acompanhar as modificações do patrimônio em virtude da atividade econômica ou social que uma empresa exerce no contexto econômico.

Para que possa executar sua função, a Contabilidade é dividida em áreas, sendo a Controladoria uma das mais importantes, já que é considerada um estágio evolutivo da própria Contabilidade, justamente porque tem como função garantir que as informações recebidas sejam confiáveis e que estejam sempre disponíveis aos gestores em suas tomadores de decisões.

Assim, a Controladoria pode ser definida como o setor de uma organização responsável pela elaboração e manutenção do sistema integrado de informações, sejam elas: contábeis, financeiras ou operacionais. De acordo com Oliveira (2009, p. 16), 
A Controladoria contribui para uma organização da qual faça parte ao desempenhar atividades como: colaborar na formação das estratégias, organizar, analisar e apresentar dados coletados, elaborar informações relevantes à administração e gerar modelos decisórios coerentes e consistentes com a missão e visão da empresa.

Em resumo, a Controladoria serve como um órgão de observação e controle da cúpula administrativa, que preocupa-se com a constante avaliação da eficácia e eficiência das atividades desenvolvidas pelos departamentos de uma empresa. É por meio dela que uma empresa consegue identificar os pontos de estrangulamento presentes e futuros que podem reduzir sua rentabilidade. A esse respeito, Monteiro e Barbosa (apud VIEIRA et al., 2012) comentam que a Controladoria tem como instrumentos principais o processo de gestão, e os sistemas de informação, os quais dão suporte ao acompanhamento dos resultados positivos das empresas.

Kanitz (1977) entende que as funções da Controladoria podem ser resumidas nas seguintes: informação: compreende os sistemas contábil-financeiro-gerenciais; motivação: referese aos efeitos dos sistemas de controle sobre o comportamento dos funcionários; coordenação: visa centralizar informações com vista na aceitação de planos; avaliação: interpreta fatos, informações e relatórios, avaliando os resultados por área de responsabilidade, por processos, por atividades etc.; planejamento: assessora a direção da empresa na determinação e mensuração dos planos e objetivos; e acompanhamento: verifica e controla a evolução e o desempenho dos planos traçados a fim de corrigir falhas ou de revisar os planos.

O setor hospitalar brasileiro é constituído pelos hospitais públicos, privados, e do terceiro setor, os quais são organizações de alta complexidade, compostos por departamentos distintos com foco no atendimento e solução dos problemas de saúde.

Para se ter uma dimensão da complexidade de gestão das organizações hospitalares, Bittar (2004) comenta que para cada instituição tem-se cerca de oito mil itens de materiais de consumo, quatro mil itens no grupo de medicamentos e mil itens no grupo de impressos próprios, como também cerca de quatro mil procedimentos possíveis, cerca de três mil tipos de exames laboratoriais e cerca de três mil possíveis diagnósticos médicos. Além disso, um hospital é uma instituição regida por leis, normas, regulamentos e portarias, advindas de diversos órgãos públicos. Assim, a gestão de um hospital deve levar em consideração tanto a sua complexa rotina operacional, quanto às normas advindas dos órgãos públicos. Por isso, contar com o auxílio de ferramentas de gestão, como a Controladoria, deve contribuir para a tomada de decisões acertadas.

\section{DISCUSSÃO}

Conforme mencionado a pesquisa bibliográfica foi realizada por meio do levantamento dos artigos publicados em português na base de dados Google Acadêmico no período de 2012 a 2018, a partir da palavrachave Controladoria Hospitalar. Dos 24 resultados encontrados, apenas 06 demonstraram os benefícios advindos da utilização da Controladoria pelos hospitais, sendo 01 pesquisa realizada em 2012, 01 em 2013, 01 em 2015, 02 em 2016, e 01 em 2017, conforme classificação cronológica.

Com relação aos resultados encontrados, tem-se que o primeiro artigo analisado referiu-se a um estudo sobre a utilização dos instrumentos da Controladoria em uma entidade hospitalar do terceiro setor, que tinha como objetivo geral analisar os instrumentos de controle de uma associação filantrópica no município de Teófilo Otoni/MG. Em relação aos resultados dessa pesquisa, foi constatado que a entidade hospitalar pesquisada utilizava a Contabilidade como um instrumento de gestão e controle interno, sobretudo por meio da Contabilidade de Custos, e não utilizava necessariamente a Controladoria e suas ferramentas.

O segundo artigo tratava-se de um estudo sobre a percepção dos gestores de um hospital privado da cidade de Florianópolis/SC com relação as funções da Controladoria. Do analisado, verificou-se que o gestor do hospital julgava o controller como sendo o receptor e destinatário de informações, direcionador, mediador de gastos, dentre outros papeis. Nesse sentido, os resultados demonstraram uma Controladoria proativa e atuante, porém 
direcionada para funções operacionais mediadas pelo gestor e pelo controller.

O terceiro artigo referiu-se a gestão de custos hospitalares no hospital Santa Casa de Misericórdia e Maternidade de Rondonópolis/MT. Da análise desse artigo, ficou claro que a gestão do hospital tentou implantar a Controladoria de maneira estratégica, ou seja, considerando o sistema de custo fundamentalmente voltado à tomada de decisão, e não somente para finalidades fiscais. No entanto, tal implantação não havia trazido resultados significativos para o hospital.

O quarto artigo teve como objetivo estudar os instrumentos da Controladoria nos pequenos e médios hospitais da cidade de Manaus/AM. A pesquisa fundamentou-se no objetivo da analisar a utilização da Controladoria em empresas de médio e pequeno porte, verificando se os hospitais analisados faziam uso da Contabilidade Financeira em tomadas de decisões e se utilizavam ou não as ferramentas da Controladoria. Nesse contexto, ficou subentendido que a Contabilidade Financeira referia-se a um instrumento de controle da Controladoria.

O quinto artigo teve como objetivo realizar um estudo da Controladoria na gestão de uma instituição hospitalar filantrópica do Sul de Santa Catarina/SC. Como resultado, essa pesquisa apresentou as características das entidades hospitalares, o histórico da contabilidade gerencial, e as funções, atribuições e desempenho da Controladoria, e complementou apresentando as ferramentas de gestão utilizadas pela mesma. Também foram apresentadas as visões dos gestores e dos colaboradores com relação aos processos executados pelo setor de Controladoria, assim como foi constatado que com implantação desse setor, as mudanças no hospital foram positivas na visão dos gestores, em especial quanto ao aperfeiçoamento dos processos. Deste modo, a pesquisa concluiu que foi possível evidenciar o auxílio gerado pelas ações do setor de Controladoria para as tomadas de decisões, como também para o crescimento da organização.

$\mathrm{O}$ sexto artigo que versou sobre o setor de Controladoria na gestão do Hospital das Clínicas da Universidade Federal de Pernambuco (UFPE) teve como objetivo analisar o funcionamento e a estrutura deste setor, identificando seu papel dentro da organização. Foi evidenciado que com o passar dos anos, o hospital passou por inúmeras transformações que se tornaram fatores preponderantes para o uso da Controladoria na organização. Sendo assim, a pesquisa realizada no artigo analisado foi de suma importância, uma vez que ocorreu no período de reestruturação do hospital, e desse modo, seu desenvolvimento e resultados contribuíram para a melhoria e desenvolvimento dos novos processos do hospital.

Por fim, o sétimo artigo que teve como finalidade principal estudar os efeitos da implantação da Controladoria em uma instituição hospitalar, tratou-se de um estudo de caso em que as informações foram abordadas de forma exploratória e através da descrição dessa implantação. Foram realizadas entrevistas que demonstraram que a organização valorizava o trabalho realizado pelo setor de Controladoria em razão das modificações implantadas e dos processos desenvolvidos por esse setor.

\section{CONCLUSÃO}

Considerando a importância do atendimento realizado pelas instituições hospitalares à população brasileira, e dada a complexidade de suas atividades, verifica-se a necessidade de ferramentas que possibilitem à essas organizações serem eficientes e produtivas. Nesse contexto, destaca-se a Controladoria e suas ferramentas - uma área da Contabilidade e um setor interno das empresas, capaz de garantir confiabilidade e disponibilidade na entrega das informações aos gestores em suas tomadores de decisões.

No entanto, verificou por meio da pesquisa bibliográfica realizada, que apesar da Controladoria ter um papel fundamental na gestão empresarial, sua utilização ainda é pouca no setor hospitalar, tratando-se de rotinas operacionais e não de ferramentas estratégicas voltadas para as tomadas de decisões.

Dessa forma, o objetivo geral dessa pesquisa foi alcançado, assim como a hipótese de que a Controladoria tem sido utilizada pelos hospitais de maneira restrita, ou seja, apenas como um instrumento de controle e não de tomada de decisão foi corroborada.

Este estudo tem considerável relevância para a comunidade acadêmica, pois remete a oportunidade de aprofundar os conhecimentos sobre o tema Controladoria no contexto do setor hospitalar, sendo as atividades realizadas pelos hospitais uma das mais importantes e também uma das mais complexas do Brasil. 


\section{REFERÊNCIAS}

BITTAR, O. J. N. V. Hospitais: administração da qualidade e acreditação de organizações complexas. Porto Alegre: Dacasa, 2004.

BRITTO, E. A.; BATISTA, F. D. Controladoria como instrumento para tomada de decisão. Centro Universitário Católico Salesiano Auxilium. Lins-SP, Unisalesiano, 2008.

FACHIN, O. Fundamentos de metodologia. 5. ed. São Paulo: Saraiva, 2006.

KANITZ, S. C. Controladoria: teoria e estudos de casos. São Paulo: Pioneira, 1977.

MARCONI, M. A.; LAKATOS, E. M. Fundamentos de metodologia científica. 5. ed. São Paulo: Atlas, 2003.

MULLER, A. N. Contabilidade básica: fundamentos essenciais. São Paulo: Afiliada, 2010.

OLIVEIRA, A. B. S. Controladoria: fundamentos do controle empresarial. São Paulo: Saraiva, 2009.

SANTOS, L. C. B. et al. Profissionais da contabilidade engajados no auxílio gerencial às micro e pequenas empresas brasileiras. Revista Brasileira de Contabilidade, n. 210, p. 56-69, nov./dez., 2014.

SILVA. H. E; SILVA NETO, I. F. ; CERQUEIRA; C. C. A. X. Evolução e teoria da contabilidade: análise da concepção acadêmica a luz da ciência contábil. 2015. Disponível em https://fapb.edu.br/wpcontent/uploads/sites/13/2018/02/ed4/6.pdf.

Acesso em: 02 dez. 2017.

VERGARA, C. S. Tipos de pesquisa em administração. Rio de Janeiro: FGV, 1990.

VIEIRA, R. P. et al. Controladoria: um estudo do uso de instrumentos de Controladoria nas médias e pequenas empresas do ramo hospitalar da cidade de Manaus (AM). MPGOA, João Pessoa, v.1, n.1, p. 78-94, 2012. Disponível em http://www.periodicos.ufpb.br/index.php/mpgoa /article/view/15083/9194. Acesso em: 02 dez. 2017.
Recebido para publicação em 20/11/2018 Aceito em 30/04/2019 